\title{
Investigating the Degree of Observing Scientific Principles in Developing the Content of the Course "Thought and Research" (TAR) in the Sixth Grade Primary School
}

\author{
Majid Bahraini Boroujeni (Corresponding author)
}

Curriculum Development

The University of Isfahan and Faculty Member of Farhangian University of Shahrekord

Tel: 98-091-3185-5595_E-mail: majid_bahraini@yahoo.com

Seyyed Ebrahim Mirshah Ja'fari

Professor of School of Education, The University of Isfahan

E-mail: sebrahimjafari@yahoo.com

Mohammad Javad Liaghatdar

Associate professor of School of Education, The University of Isfahan

E-mail:mjavad_liaghatdar@yahoo.com

Ahmad Reza Nasr Esfahani

Professor of School of Education, The University of Isfahan

E-mail: arnasr@edu.ui.ac.ir

Received: August 6, 2014

doi:10.5296/jse.v4i4.6120
Accepted: Nov. 11, 2014 Published: November 1, 2014

URL: http://dx.doi.org/10.5296/jse.v4i4.6120

\begin{abstract}
The purpose of the present study was to investigate the degree of considering the scientific principles in developing the content of the course "Thought and Research"(henceforth TAR) in the sixth grade primary school. The method employed in this applied research was survey study and content analysis technique is used as well. The data were collected quantitatively and qualitatively (mixed method research). The population consisted of instructors, authors, experts and teachers in Isfahan and Chahar Mahal and Bakhtiari Provinces. A 44 individual
\end{abstract}


sample of instructors and authors were selected from the population. For other groups, Random Stratified Sampling method was used and respectively 18 and 264 participants were selected. In quantitative section, 95 classes were observed and 180 participants were purposefully interviewed face to face in a semi-structured method. The data was collected using questionnaires, interviews, and observations. To determine the validity, both content and construct validities were used. KMO (in order to check the internal consistency of items) for teachers and observers questionnaires were respectively $(0.907,0.740)$ and questionnaires reliability in Cronbach's alpha were respectively 0.92 and 0.76 . According to the teachers and experts questionnaires, the principles of developing the content were employed were at moderate level $(\bar{X}=3.48 \& \mathrm{p} \leq 0.05)$, and according to the observations they were employed at low level $(\bar{X}=2.75 \& \mathrm{p} \leq 0.05)$. Therefore, it is recommended that (TAR) course should be reviewed by educational experts, especially curriculum planners, expert teachers. In addition, according to the results of investigations on scientific principles, learners, interests, cultural and regional conditions, sufficient time and facilities as well as the three learning domains the ground of its effective implementation should be provided.

Keywords: national curriculum, curriculum elements, Thought and Research Course, curriculum content. 


\section{Introduction}

Nowadays, educational system is considered as one of the basic tools in the comprehensive development of all countries. Sixth grade primary school is one ofthe most important courses in educational system. If children do not learn the required skills in this section, the opportunity to compensate it in the future will be difficult.

Among the required skills for learning this period are metacognitive skills which can make students more efficient. Therefore, nowadays, in developing educational contents and processes, multiple approaches are presented and one of the most important objectives of them is thinking. Some of the experts such as Robinson believe that the primary objective of education should be fostering thoughtful human beings enjoying exploring minds because thought is a process that more enjoys acquisitive mode. As a result, always, different ideas have always been presented about how though is taught in educational systems (De Buno, 1991).

The most important presented theories indicate the teaching of thinking skills both directly and indirectly. The direct approach indicate that to teach thinking skills, a course with the same name should be included. The second viewpoint emphasizes that using different educational topics one can teach the learners how to think (FathiAzar, 2003).

One of the gaps available in Iran's educational system is paying too much attention to theoretical educations and the lack of attention to learning with thought, vision and understanding. Among the reasons of confirming this claim is paying attention to the results related to TIMSS $^{1}$ and PIRLS ${ }^{2}$ tests because the results of these tests indicate that Iranian students were poor in answering the questions whose contents were inferential and evaluative and deductive and their mean performance was significantly lower than the international mean (TIMSS and PIRLS Centers for International Studies, 2006).

In addition to the mentioned cases, the results of other studies indicate that a lot of alumni lack skills and tendencies of critical thinking, many of them do not have the power of analyzing complicated issues and are incapable in encountering high level issues (Kiani et al. 2012; Akhundzadeh et al. 2011; Haghani et al. 2010; Javidi and Abdoli, 2010; Masouri and Nouri, 2009; Anjafi et al. 2009; Athari et al. 2009). Furthermore, the experts refer to the lack of attention of educational systems to teaching thinking skills.Eisner (1983), in a study titled as "the kinds of schools we need" refers to the problems of the schools of today and states that the schools of today, only the skills of reading, writing and calculating are emphasized, while these skills are not naturally valuable and in are empty of virtue in terms of education.

Now, the authorities of education identify the weaknesses of educational system and by developing a new educational system are to pay attention to teaching thinking to students and amending the curriculum. One of these methods is developing the course " TAR" in the curriculum of sixth grade primary school. Two years after implementing the course " TAR", the researchers meant to investigate the degree of observing the scientific principles based on 
developing the contents of the course " TAR" in the sixth grade of primary school form teachers', experts' and observers' viewpoints according to Tyler's four curriculum principles (setting objectives, developing contents,implmenting and evaluating) in the form of following questions:

From teachersexperts and instructorspoint of view, to what extent is the contents of the course " TAR" in the sixth grade primary school developed based on scientific principles?

From observers' point of view,to what extent is the contents of the course " TAR" in the sixth grade primary school developed based on scientific principles?

Regarding the results of interviews, what evaluation do the sample have about the observing scientific principles of developing the content of the course " TAR"?

\section{Method}

The type of the research was survey and content analysis using checklists. In terms of aims, the research was applied and in terms of collecting data, it is a Mixed Method or Integrated Method.

\subsection{Population and sample}

The population of the quantitative part of the study includes experts, teachers, and instructors of Isfahan and ChaharMahal and Bakhtiari Provinces and the authors of the book "TAR" in the Compilation Office of the Ministry of Education (table 1).

Table 1 . The frequency of the population and the sample separated by provinces

\begin{tabular}{|c|c|c|c|c|}
\hline & $\begin{array}{l}\text { Position } \\
\text { province }\end{array}$ & Isfahan & ChaharMahal & Total \\
\hline \multirow[b]{2}{*}{ Experts and authors } & Population & 14 & 8 & 22 \\
\hline & Sample & 14 & 8 & 22 \\
\hline \multirow[t]{2}{*}{ Teachers and instructors } & Population & 2572 & 646 & 3218 \\
\hline & Sample & 197 & 134 & 304 \\
\hline \multirow[t]{2}{*}{ Observing the process of the class } & Population & 3046 & 586 & 3632 \\
\hline & Sample & 54 & 41 & 95 \\
\hline
\end{tabular}

The population of the qualitative part of the research includes: a) observing the teaching and learning processes of 95 classes of "TAR" course. And b) interviews. In the research, for qualitative sampling, purposive sampling including the convenient sampling method and stratified purposeful sampling were employed. In the research, interviews were administered on 180 participants of the population. In other words, in order that the quantitative findings be more ensured, the researchers conducted qualitative research as well. The degree of the consistent between the survey studies and the evidence obtained from qualitative research causes more confidence to the findings results from the survey study (Nasr and Sharifian, 2007). 


\subsection{Data collecting instrument and determining validity and reliability:}

The research data were collected using a researcher-made questionnaire, interview and observation. To determine the validity of the questionnaires of a) teachers' content analysis, and b) observers' forms, both content validity and construct validity were used using factor analysis. To investigate the content validity, the supervisor's and advisor's ideas and also those of five experts of curriculum design were used. To investigate the internal consistency of the questionnaire items, the KMO index was calculated. This value was 0.90 for the questionnaire of teachers, and 0.79 for the form of observers. Comparing these numbers with the norm of 0.7 and using Bartlett's test of sphericity in the significance level $(p>0.01)$ indicate that the items enjoy a high level of internal consistency and the three questionnaires enjoy construct validity. In addition, the validity of the interview questions was confirmed by 5 individuals of university professors and experts of curriculum design.

Table 8. Calculating the construct validity using factor analysis

\begin{tabular}{|c|c|c|c|c|}
\hline \multirow[t]{2}{*}{ Component } & \multirow{2}{*}{ KMO } & \multicolumn{3}{|c|}{ Bartlett's sphericity test } \\
\hline & & $\chi^{2}$ & df & Sig \\
\hline Principles of choosing contents & $0 / 838$ & $497 / 6636$ & 15 & $0 / 000$ \\
\hline Principles of presenting contents & $0 / 745$ & $288 / 386$ & 10 & $0 / 000$ \\
\hline Principles of compatibility of contents & $0 / 782$ & $541 / 888$ & 21 & $0 / 000$ \\
\hline Principles related to teaching style & $0 / 773$ & $387 / 321$ & 6 & $0 / 000$ \\
\hline Principles of organizing contents & $0 / 725$ & $291 / 194$ & 6 & $0 / 000$ \\
\hline Questionnaires of teachers and instructors (total) & $0 / 907$ & $3457 / 59159$ & 325 & $0 / 000$ \\
\hline Contents of observers & $0 / 740$ & $71 / 445$ & 6 & $0 / 000$ \\
\hline
\end{tabular}

The reliability of questionnaire items was calculated through primarily on a 40 individuals group by Cronbach's alpha.

Table 9. Reliability related to the three questionnaires and the scientific principles of developing contents

\begin{tabular}{|l|c|c|l|c|c|}
\hline \multicolumn{1}{|c|}{ Variable } & Cronbach's $\alpha$ & $\begin{array}{c}\text { Number } \\
\text { of items }\end{array}$ & \multicolumn{1}{|c|}{ Variable } & Cronbach's a & $\begin{array}{c}\text { Number } \\
\text { of items }\end{array}$ \\
\hline Principles of choosing contents & $0 / 794$ & 6 & Principles of organizing contents & $0 / 754$ & 4 \\
\hline Principles of presenting contents & $0 / 713$ & 5 & $\begin{array}{l}\text { Content analysis of } \\
\text { questionnaires for teachers }\end{array}$ & $0 / 927$ & 26 \\
\hline $\begin{array}{l}\text { Principles of compatibility of } \\
\text { contents }\end{array}$ & $0 / 788$ & 7 & $\begin{array}{l}\text { Content analysis of } \\
\text { questionnaires for observers }\end{array}$ & $0 / 720$ & 14 \\
\hline Principles related to teachingstyle & $00 / 789$ & 4 & & & \\
\hline
\end{tabular}


To evaluate the reliability of interviews: firstly, 14 participants participated in face to face semi-structured interviews and the interviews were reordered and then, using the method of writing down objectively and attentively the voice of interviewees, typing and summarizing the main notes stated by them and categorizing them, all subjects were written, the summary of subjects and the determined categories were submitted to three individuals aware of research methods.

To evaluate the reliability of observation: this was done in two stages. In the first state, the method of criterion-based inter-observer to which indicates the degree of the consistency of scores of learned observers and those of the researchers and also the method of inter-observer reliability which indicates the degree of consistency of observers during real collection were used. The consistency coefficient in the first method was 0.87 and the consistency coefficient in the second method was 0.89 . In the second stage, to calculate the reliability of the final form of observation, the method of Cronbach's alpha was used and the coefficient was calculated equal as 0.720 .

\subsection{Data collection and data analysis methods:}

teachers', instructors', experts and authors' questionnaires were distributed either in person or through regular mail and e-main among them and after following up, a number of 18 individuals of experts of offices, 40 individuals of instructors of the course "TAR" and 4 individuals of authors, and 264 individuals of teachers of the sixth grade primary school answered the questionnaires.

To observe the process of teaching, the observers, by attending two times in 95 classes, remained in the last time of the classes, and observed normally the process of teaching and learning and using a chronometer at the end of each minute, based on the dominating atmosphere of the process of learning and teaching of the classes, identified the frequency of variables in the observation forms in front of questions related to the scientific principles of contents (recording observation based on time).In the second stage, they organized frequencies in the Likert scale (observational evaluation). This issue was done by coordinating with the supervisor and advisor as well as five of the teachers successful in teaching the course "TAR". The mentioned method asks not only the observed variables related to observes to record the particular behaviors, but also to evaluate some of them on the a graded scale (Gull et al. 2008).

The semi-structured interview was administered face to face and non-face to facewith 180 participants. Then, by writing down and typing the participants' statements, categorizing them and determining the reliability of the categorization, the mentioned points were put in the related categories.

\section{Research findings}

2.1 The first question: from teachers', experts' and instructors' viewpoint, to what extent are the contents of the course "TAR" in the sixth grade primary school developed based on scientific principles? 


\section{Macrothink}

Table 10. the descriptive data and the test of significance related to respondents' attitudes

\begin{tabular}{|l|c|c|c|c|}
\hline \multicolumn{1}{|c|}{ Category } & $\mathrm{X}$ & $\mathrm{S} . \mathrm{D}$ & $\mathrm{t}$ & $\mathrm{sig}$ \\
\hline Principles related to teaching style & $3 / 60$ & $0 / 845$ & $12 / 41$ & $0 / 00$ \\
\hline Principles of presenting contents & $3 / 59$ & 0687 & $14 / 98$ & $0 / 00$ \\
\hline Principles of choosing contents & $3 / 52$ & $0 / 712$ & $12 / 73$ & $0 / 00$ \\
\hline Principles of compatibility of contents & $3 / 40$ & $0 / 731$ & $9 / 65$ & $0 / 00$ \\
\hline Principles of organizingcontents & $3 / 30$ & 0847 & $5 / 99$ & $0 / 00$ \\
\hline Total & $3 / 48$ & $0 / 636$ & $13 / 15$ & $0 / 00$ \\
\hline
\end{tabular}

Regarding the results, the respondents' attitudes to the observance of scientific principles in developing the content of the course "TAR" was at moderate level $(\bar{X}=3.48)$, which separately, the principles based on teaching style with the mean $(\bar{X}=3.60)$, the principles based on presenting the content with the mean $(\bar{X}=3.59)$, the principles based on selecting the content with the mean $(\bar{X}=3.52)$, the principles based on compatibility with the mean $(\bar{X}=3.40)$ and the principles based on organizing the content with the mean $(\bar{X}=3.30)$ respectively where the scores of all parameters were bigger than the hypothetical mean 3. According to the results of univariate t-tests $(\mathrm{p}>0.01)$, this difference was significant in all investigated indices. Therefore, the null hypothesis stating the equality of the mean score with the hypothetical mean (3) is not accepted and the respondents' attitudes to the observance of scientific principles in developing the content of the book "TAR" is at the moderate level $(\bar{X}=3.48)$.

In addition, there is no difference between the respondents' attitudes separated by the provinces of workplace and gender regarding the observance of principles based on organizing the content. In other words, the respondents of Isfahan andChaharMahal and Bakhtiari in both genders, male and female, believe that in developing the book "TAR" of the sixth grade primary school, the principles related to developing the content is observed at the moderate and higher levels.

t-tests of two independent and variance analysis indicate that there is no significant difference between the attitudes of males and females, the province of workplace, organizational position, field of study, the interaction of two variables of gender and work experiences and the interaction of gender and organizational position regarding the observance of scientific principles in contents. 


\section{Macrothink}

Table 11. Friedman rank analysis test regarding the scientific principles related to the contents

\begin{tabular}{|c|c|c|c|c|c|}
\hline Content principles & Rank mean & $\mathrm{N}$ & $\chi^{2}$ & $\mathrm{df}$ & sig \\
\hline Teaching style & $3 / 43$ & \multirow{5}{*}{302} & \multirow{5}{*}{$73 / 896$} & \multirow{5}{*}{4} & \multirow{5}{*}{$0 / 00$} \\
\hline Presenting the content & $3 / 33$ & & & & \\
\hline Selecting the content & $2 / 99$ & & & & \\
\hline Compatibility & $2 / 68$ & & & & \\
\hline Organizing the content & $2 / 57$ & & & & \\
\hline
\end{tabular}

The results of Friedman variance analysis indicate that the rank mean, respondents' attitudes to the observance of scientific principles related to the content of the course "TAR", the principles related to teaching style with 3.43 , principles of presenting the content with 3.33 , principles of selecting the content with 2.99 , principles of compatibility with 2.68 and principles of organizing the content with 2.57 have the highest mean scores respectively.

2.2.The second research question: from observers' viewpoint, to what extent are the contents of the course "TAR" in the sixth grade primary school developed based on scientific principles?

Table 12. the descriptive data and the test of significance related to applying scientific principles related to the content based on observations

\begin{tabular}{|l|l|l|l|l|l|l|l|}
\hline Row & Category & $\mathrm{N}$ & $\mathrm{X}$ & $\mathrm{S} . \mathrm{D}$ & $\mathrm{t}$ & $\mathrm{df}$ & $\mathrm{sig}$ \\
\hline 1 & $\begin{array}{l}\text { The course content is understandable for } \\
\text { students. }\end{array}$ & 95 & $3 / 19$ & $0 / 589$ & $3 / 13$ & 94 & $0 / 002$ \\
\hline 2 & $\begin{array}{l}\text { The course content make student think on, } \\
\text { analyze and solve issues. }\end{array}$ & 95 & $3 / 12$ & $0 / 742$ & $1 / 52$ & 94 & $0 / 132$ \\
\hline 3 & $\begin{array}{l}\text { Different levels of cognitive, emotional } \\
\text { and psycho - motor aspects are paid } \\
\text { attention to. }\end{array}$ & 95 & $2 / 66$ & $0 / 738$ & $4 / 44$ & 94 & $0 / 000$ \\
\hline 4 & $\begin{array}{l}\text { The content is compatible with } \\
\text { time,predicted facilities and equipment for } \\
\text { teaching. }\end{array}$ & 95 & $2 / 03$ & $0 / 831$ & $11 / 35$ & 94 & $0 / 000$ \\
\hline 5 & Total & 95 & $2 / 75$ & $0 / 538$ & $4 / 52$ & 94 & $0 / 000$ \\
\hline
\end{tabular}

Regarding the results, the mean scores observers regarding applying scientific principles in developing content in the course "TAR" was $(\bar{X}=2.75)$ which this mean score is smaller than the hypothetical mean 3 . According to univariate $t$-test $(p>0.05)$, this difference is significant. Therefore, the null hypothesis stating the equality of mean score with hypothetical mean 3 is 


\section{Macrothink}

rejected. In other words, applying scientific principles in developing the content is at low level $(\bar{X}=2.75)$ in the process of teaching and learning the course "TAR".

The data indicate that the observers' attitudes to the principles of choosing the content includes understandability of the content with the mean $(\bar{X}=3.19)$, persuading students to thinking, analyzing and solving the problem with the mean $\left(\bar{X}_{=3.12}\right)$, paying attention to cognitive, emotional and psycho-motor domains with the mean $(\bar{X}=2.66)$, compatibility with the predicted facilities, equipment and time with the mean $(\bar{X}=2.03)$. Based on the observers' attitudes, there is no difference between classes in terms of teachers' work experiences, and field of study regarding applying scientific principles in the content.

According to the observers' attitudes, the results of two-way ANOVA indicate that the effect of the province of workplace on the process of teaching and learning of students was different from that of students and the teachers of Isfahan Province have better performance than the teachers of Chahar Mahaland Bakhtiari Province in applying scientific principles in the course "TAR". In addition, female teachers have better performance than male ones, but the interaction of the two variables of province and gender regarding this performance is not significant.

2.2 The third research question: regarding the results of the interviews, how is the evaluation of the research sample regarding applying scientific principles in developing the content of the course "TAR". 


\section{$\triangle 1$ Macrothink}

Table 14. the results obtained from categorizing interviews to the question of evaluating the content of the course "TAR"

\begin{tabular}{|c|c|c|c|}
\hline Number & $\begin{array}{l}\text { Index (category) extracted related the element of the content of the course "TAR" of } \\
\text { the sixth grade primary school }\end{array}$ & Frequency & Percentage \\
\hline 1 & $\begin{array}{l}\text { Principles of presenting the content (attention to time, facilities, equipment, being } \\
\text { question-oriented and emphasis on group work }\end{array}$ & 100 & $55 / 5$ \\
\hline 2 & $\begin{array}{l}\text { Attention to compatibility of the content (attention to cultural and local, climatic and } \\
\text { geographical conditions, cultural, social and ethical values, age, gender, prior } \\
\text { experience of students) }\end{array}$ & 52 & 28 \\
\hline 3 & Attention to the principles of choosing the content (interests, persuasion to thinking) & 50 & 27 \\
\hline 4 & $\begin{array}{l}\text { Reinforcing skills (thinking, inferring, solving observational problems, listening, } \\
\text { judging, group discussion, confidence, personal and interpersonal relations) }\end{array}$ & 20 & 11 \\
\hline 5 & $\begin{array}{l}\text { Attention to teaching style (attention to Divine revelations, attention to curiosity, } \\
\text { relevance to facilities, understanding and advocating religious values, continuous } \\
\text { learning) }\end{array}$ & 10 & 5 \\
\hline 6 & $\begin{array}{l}\text { Principles of organizing contents ( relationship with other sciences,logical Journey } \\
\text { of presenting the content such as presenting the content top to bottom and form } \\
\text { objective to subjective) }\end{array}$ & 8 & $4 / 4$ \\
\hline
\end{tabular}

The results indicate that 55.5 percent of the teachers and instructors, to some extent, believe in observing scientific principles in presenting the content, 28 percent in observing content compatibility, 27 percent in attention to the principles of choosing the content, 11 percent in the effect of the course "TAR" in reinforcing thinking, inferring, solving observational problems, listening, judging, group discussion, confidence, personal and interpersonal relations skills, 5 percent in teaching style and 4.4 percent of the believe in the principles of organizing the content.

\section{Discussion, Conclusion and Suggestions}

In the national curriculum which is one of the sub-systems of the Strategic Document of Transforming Education, the element of thought and reason has the first rank and it is pivotal. Accordingly, the course "TAR" of the sixth grade primary school was developed and for the second year, it has been taught.

Regarding the results, the mean score of the attitudes of teachers, instructors and experts to observing scientific principles of developing the content (principles of choosing the content, principles of presenting the content, principles of compatibility, principles related to teaching style, principles of organizing the content, and the total of principles are 3.52, 3.59, 3.40, 3.60, 3.30 and 3.48 respectively which the score of all parameters is bigger than the hypothetical mean 3. In other words, the attitude of the respondents to observing scientific principles in developing the content of the book course "TAR" is in the moderate level (to some extent) $(\bar{X}=3.48)$. 
In addition, there is no difference between the attitudes of teachers and those of experts separated by the province of workplace and gender regarding observing scientific principles in developing the content.

The results of Friedman variance analysis test indicate that the attitudes of the teachers, instructors and experts to observing scientific principles in developing the content, respectively, assigned to themselves the principles related to teaching style with 3.43 , principles of presenting the content with 3.33, principles of selecting the content with 2.99, principles of compatibility with 2.68 and the principles of organizing the content with 2.57 mean rank.

The results of the observers indicate that observing scientific principles in developing the content of the course "TAR" was at low level $(\bar{X}=2.75)$. They believe that the principles of choosing the content includes the understandability of the content $(\bar{X}=3.19)$, persuasion of the content to thinking, analyzing and solving problems $(\bar{X}=3.12)$, attention of the content to cognitive, emotional and psycho-motor domains $(\bar{X}=2.66)$, compatibility of the content with the predicted facilities, equipment and time $(\bar{X}=2.03)$ has been observed at low level.

The results of the observers indicate that the principles of scientific principles related to the contents of the classes of females are more observed than that of the classes of males. The results of the interviews indicate that 55 percent of teachers and instructors, to some extent, believe in observing the scientific principles of presenting the content, 28 percent in observing the principles of content compatibility and 20 percent in the role of the course "TAR" in reinforcing skills of thinking, inferring, solving problems, observing, listening, judging, work group, confidence, personal and interpersonal relations.

This study is the first one which investigates the issue of the course "TAR"; therefore, the related research indicate that the contents of most of course books have not particular attention to learning with thinking and reasoning in students. Among the studies conducted on this field, the results of the study of Kiani et al. (2012), Akhundzadeh et al. (2011), Haghani et al. (2010), Javidi and Abdoli, 2010; Masouri and Nouri, 2009; Anjafi et al. 2009; Athari et al. 2009, HashemianNejad (2001),TIMSS and PIRLS Centers for International Studies, (2006) and Project ABC (Advancement Based on Competency), Kiamanesh (2000) which indicate that many students and graduates in the society of today, lack skills and tendencies of thinking and the power of analyzing and solving complicated social problems and in encountering high level issues, they are unable.

One of the ways of fostering thinking is serious attention to applying the scientific principles related to the content; therefore, the interests, age and needs of learners should be considered in order that through them, reinforcing attributes such as self-esteem, listening skills, 
ascendancy, and inquiry should be develop in students. These results are consistent with the results of the studies of Kite (1991), Sasseville (1994), Santi (1993), Smith (1999) .

The content of books should make students think. The course "TAR" has been successful in this issue to some extent. This achievement is consistent with the results of Wissinger (2004), Paul and Elder (2005), Tiwari et al. (2006), Mir Afshar et al. (2013), Kitot, Ahmad and Seman (2010), Yang, Newby and Bill (2005), Kuhn, Shaw and Felton (1997), Anderson et al. (2001), Schwartz et al. (2003) which indicate that the content of course books are not so effective in fostering thinking of graduates.

Based on the results, it is suggested that the content of the book "TAR" should be revised by a group of curriculum specialist as well as Philosophy of Education specialists and expert teachers. Then, the results of the research conducted on this domain and the observance of scientific principles related to the content should be reviewed and revised. Therefore, paying attention to the parameters such as students' needs and interests, cultural, national and global values, observing the quality of story books and workbooks for student in terms of editing, lining, picturing, and coloring and also in terms of size, relevance of the content to the predicted time, facilities and equipment are necessary. In addition, it is suggested that some of the prescriptive activities of the course "TAR" should be organized in the semi-prescriptive and optional sections. The ground of presenting the content includes preparing and distributing the teaching aids, paying attention to the required time for teaching, using creative and interested teachers and holding educational workshops for them, organizing female teachers for teaching this course as much as possible and amending and deleting some course's activities are among the necessary cases.

\section{References}

Athari, Z. (2009). Evaluating the skills of critical thinking and its relationship with the rankings ofNational University entrance exam among the students of Isfahan University of Medical Sciences. Iranian Journal of Medical Education, 9(1), 5-12.

Athari, Z. (2012). Investigating the role of curriculum in the skills of critical thinking in the students of Isfahan University and Isfahan University of Medical Sciences. PhD thesis of Curriculum Planning. University of Isfahan, Faculty of Education and Psychology.

Akhundzadeh, K., Ahmadi Tehrani, H., Salehi, Sh. \&Abedini, Z. (2010). Critical thinking in the field of nursing in Iran. Iranian Journal of Medical Education, 11(3), 212-221.

Anjafi, F., Zera'at, Z., Soltan Mohamadi, Z., Ghabchi, K., \& Kohan, F. (2009). critical thinking skills of Engineering and Humanity Students. Journal of Education Strategies, 2(1), $19-22$.

Anderson, A., Howe, C., Soden, R., Halliday, J., \& Low, J. (2001). Peer interaction and critical thinking skills in further education students. Instructional Science, 29, 1-32. http,//dx.doi.org/10.1023/A,1026471702353

DeBono, E. (1991). Learning to think; Thinking to Learn. OECD, Program press. 


\section{Macrothink}

Journal of Studies in Education

ISSN 2162-6952

2014, Vol. 4, No. 4

Elder, L., \& Paul, R. (2004). Critical thinking development, a stage theory. Dillon Beach, CA, Foundation for Critical Thinking.

FathiAzar, E. (2008). Teaching methods and skills. Tabriz, University of Tabriz.

Fisher, R. (2006). Education and thought. F. Kianzadeh (Trans.). Ahwaz, Rasesh.

Gull, M., Burg, W., \& Gull, J. (2008). Qualitative and quantitative research methods in humanities, education and psychology. A. Nasr et al. (Trans.). Tehran, SAMT.

Haghani, F., Aminian, B., Kamali, F., \& Jamshidian, S. (2010). Critical thinking skills and their relationship with emotional intelligence in the students of the primary clinical course of Isfahan University of Medical Sciences. Iranian Journal of Medical Education, 10(5), 906-917.

Javidi, T., \& Abdoli, A. (2009). The process of transformation of critical thinking in the students of Ferdowsi University of Mashhad. Journal of Education and Psychology, 11(2), 103-120.

Kiani, M., Afshinju, M.,Poormemari, M., \& Amini, K. (2012). Comparing critical thinking and its grounding factors in nursing students and nurses working in selected hospitals of Zanjan University of Medical Sciences. Journal of Zanjan University of Medical Sciences, 20(78), 112-121.

Kuhn, D., Shaw, V., \& Felton, M. (1997). Effects of dyadic interaction on argumentative reasoning. Cognition and Instruction, 287-315. http,//dx.doi.org/10.1207/s1532690xci1503_1

Kitot, A. K. A., Ahmad, A. R., \&Seman, A. A. (2010). The effectiveness of inquiry teaching in enhancing students' critical thinking. Procedia - Social and Behavioral Sciences, 7(0), 264-273.

Mirafeshar, S., Khanabadi, M., Azadnia, A., \& Soltani, S. (2013). Investigating the efficacy of teaching the strategies of self-learning on educational improvement of female students of the fifth grade primary school in Yazd. Journal of Research on Curriculum Planning, 9(34).

Mansouri, S., \& Nouri, A. (2009). Comparing the thought of smart school students and Normal school ones of the high schools of Tehran. Conference proceeding of the modern methods in school management in the third millennium.

Ministry of Education (2011). The Document of Basic transformation of Education. Tehran, Research and Educational Planning Organization.

Ministry of Education (2011). National Curriculum of the Islamic Republic of Iran. 5th edition. Tehran, Research and Educational Planning Organization.

Ministry of Education (2006). Comparing the performance of the students of the Provinces of Iran in courses of Mathematics and TAMES Sciences (2003) of the fourth grade of primary school. Tehran,Institute of Education Studies. TIMSS and PIRLS Centers for International Studies. 


\section{Macrothink}

Journal of Studies in Education

ISSN 2162-6952

2014, Vol. 4, No. 4

Nasr, A., \& Sharifian, F. (2007). Qualitative and Quantitative and mixed method approaches in educational research. Journal of Hozeh and University, 13(53), 7-24.

Ornestien, A., \&Hunkins, F. (1997). Curriculum, Foundation, Principles and Issues. New York, Prentice.

Santi, M. (1993). Philosophizing and Learning to think, Some Proposals for a qualitative evaluation. Thinking, 10(3), 15-23.

Smith, F. (1992). To Think, In Language Learning and Education. London. Routhledge.

Smith, G. (1999). Review of Philosophy Gym, 25 Short Adventures in Thinking. By Stephen Law. Critical and Creative Thinking, 1(12), 46-47.

Schwartz, B. B., Neuman, Y., Gil, J., \&Ilya, M. (2003). Construction of collective and individual knowledge in argumentative activity. The Journal of the learning Science, 12(2), 219-256. http,//dx.doi.org/10.1207/S15327809JLS1202_3

Safi, A. (2003). The plan of researcher-teacher in Education (challenges and solutions). Quarterly of Management in Education. No. 23 and 43.

Sasseville, M. (1994). Self-esteem, Logical skills and philosophy for Children Thinking, 11(2), $30-33$.

Tiwari, A., Lai, p., So, M., \& Yuen, K. (2006).A comparison of the effect of problem based learning and lecturing on the development of student critical thinking. Medical Education, 40, 547-554. http,//dx.doi.org/10.1111/j.1365-2929.2006.02481.x

Weissinger, P.A. (2004).critical thinking meta cognition and problem-based learning. In tang seng (ed).thomson. Singapor.

Yang, Y. T. C., Newby, T. J., \& Bill, R. L. (2005). Using Socratic questioning to promote critical thinking skills through asynchronous discussion forums in distance learning environments. The American Journal of Distance Education, 19(3), 163-181. http,//dx.doi.org/10.1207/s15389286ajde1903_4 